\title{
Lactate Dehydrogenase Isoenzyme 3 Measurement
}

National Cancer Institute

\section{Source}

National Cancer Institute. Lactate Dehydrogenase Isoenzyme 3 Measurement. NCI

Thesaurus. Code C74889.

The determination of the lactate dehydrogenase isoenzyme 3 present in a sample. 